\title{
Las ONG de "desarrollo" frente a la pobreza y la desigualdad
}

\section{José María Vera Villacian'}

Resumen: Las Organizaciones no Gubernamentales de Desarrollo (ONGD) han sido y son un actor esencial en la política de Cooperación Española, en la sensibilización de la sociedad y en la capacidad para incidir y provocar cambios dirigidos hacia una mayor justicia social. En este artículo se analiza su historia, presente y desafíos futuros, desde las lentes de su relevancia e influencia política y social. Se afirma su rol como actores importantes y necesarios, la exigencia de responder a la crisis climática y de desigualdad, y las alternativas para mantener un papel significativo, aunque no siempre protagonista, de los cambios necesarios. La valentía e inteligencia política, la humildad y la determinación, como claves de acción en un entorno político difuso y polarizado.

Palabras clave: Cooperación Internacional, ONGD, Justicia Global, Desigualdad, Cambio Climático, Influencia.

The "Development NGOs" in the face of poverty and inequality

Abstract: Non-Governmental Organisations for Development have been and are an essential actor in the politics of Spanish Cooperation, when it comes to raising awareness and when it comes to their capacity to bring about changes directed at creating greater social justice. This article
Les ONG de "développement" face à la pauvreté et aux inégalités

Résumé: Les organisations non gouvernementales pour le développement ont été et sont un acteur essentiel de la politique de la coopération espagnole, tant au niveau de la sensibilisation que de leur capacité à provoquer des changements visant à créer une plus grande justice sociale. Cet article

' Consultor Internacional, ex Director Ejecutivo de Oxfam.. 
examines their history and present, as well as future challenges from the point of view of their political and social relevance and influence. It stresses their role as important and necessary actors, and the need for their response in the face of climate change and rising inequality, describing how they could maintain a significant, though not always leading, role in bringing about necessary changes by offering political courage and intelligence, humility and determination as key factors in a confusing and polarised political world.

Key words: International cooperation, NGOD, Global Justice, Inequality, Climate Change, Influence. examine leur histoire et leur présent, ainsi que les défis futurs, du point de vue de leur pertinence et de leur influence politiques et sociales. II souligne leur rôle en tant qu'acteurs importants et nécessaires, ainsi que la nécessité de leur réponse face au changement climatique et à l'augmentation des inégalités, en décrivant comment ils pourraient conserver un rôle significatif, bien que pas toujours prépondérant, dans la réalisation des changements nécessaires en offrant courage et intelligence politiques, humilité et détermination, facteurs clés dans un monde politique confus et polarisé.

Mots clé: Coopération Internationale, ONGD, Justice Globale, inégalité, Changement Climatique, Influence.

\section{Introducción y premisas de partida}

Las Organizaciones no Gubernamentales de Desarrollo (ONGD) han sido y son un actor central de la Cooperación Internacional pública y privada y del activismo por la justicia social. Como expresiones de la solidaridad internacional de colectivos y sectores de la sociedad civil, su capilaridad y diversidad han influido y fortalecido esta política, desbordando su acción a través de cientos de iniciativas entre organizaciones españolas y del sur global.

En este artículo se hace un breve repaso a su pasado, sin agotar el recorrido histórico, para extraer lecciones que sirvan para construir el futuro. A continuación, se describe la encrucijada en la que se encuentran hoy, en medio de la pandemia del Covid 19 que ha provocado una dura crisis en España y en el mundo, abriendo al tiempo oportunidades y reforzando urgencias en los retos indispensables que enfrentamos como humanidad. Finalmente se desarrollan los principales cambios que deberían asumir las ONGD para seguir siendo relevantes y crecer en capacidad de influir aquellos sistemas sociales, económicos y políticos que requieren de transformaciones hondas.

El eje del artículo es, por lo tanto, el de la relevancia e influencia para el cambio a escala. El autor es consciente de que hay otros abordajes posibles, asociados 
con la sostenibilidad financiera, los equipos humanos, las alianzas, la acción humanitaria, los principios y los valores... Aunque se penetra algo en estos campos, determinantes también para el futuro del sector, la mirada a las organizaciones es a través de su influencia social y política.

A pesar de compartir algunos elementos comunes de principios, cultura y estrategia, las ONGD son diversas. En ocasiones se desglosará el análisis para responder a esa diversidad, aunque en otras se realizará una mirada al sector en su conjunto. Las referencias serán normalmente a las ONGD españolas, sean o no parte de familias o redes internacionales. En algunos casos se extenderá el análisis a las grandes organizaciones internacionales, iNGO.

Como se verá a partir del capítulo 4, las fronteras entre ONG del norte y del sur se han ido difuminando, no para desaparecer, pero sí para hacerse más complejas. Dicho esto, en algunas partes del capítulo, sobre todo al hablar del pasado, seguiremos refiriéndonos a organizaciones del sur global como las principales socias y alianzas de las ONGD españolas.

Finalmente, cabe recordar que la mirada tanto al pasado como al futuro de las ONGD está pasada por el tamiz de la experiencia del autor, en Intermón, luego Oxfam, en la Coordinadora de ONGD, desde la Secretaría General Iberoamericana y a través de la actividad y relaciones con compañeras y compañeros de otras ONGD, en España y en el mundo.

\section{Relevancia e influencia para la transformación social y política}

Como hemos indicado, este recorrido histórico y propuesta se realiza desde la mirada de la relevancia e influencia de las ONGD, en la política de Cooperación al Desarrollo y en otras que afectan a su misión. En este punto se expone a qué nos referimos con estas dos características de las organizaciones.

Según la RAE:

Relevancia: Importancia o significación que destaca de algo.

Influencia: Poder de una persona o cosa para determinar o alterar la forma de pensar o de actuar de alguien. 
Nos referimos por lo tanto a organizaciones que son consideradas importantes, que destacan, pero que usan esa relevancia para alterar los sistemas injustos e insostenibles que provocan exclusión.

Qué no es (necesariamente) una ONG relevante e influyente. Una organización:

- Grande. El volumen, aunque ayuda, no implica siempre influencia. Hay organizaciones grandes con una influencia limitada y hasta cierto punto menor, si se compara con otras pequeñas.

- Conocida. De nuevo el conocimiento de marca ayuda y mucho, pero ni es imprescindible ni es garantía de influencia para el cambio.

- Bien gestionada y que ejecuta correctamente sus proyectos. Algo indispensable para hacer buen uso de los recursos humanos y financieros a su disposición, pero que no implica un impacto más allá de los objetivos acotados de cada proyecto o respuesta humanitaria.

- Con una teoría de cambio. Toda organización necesita una, la cuestión de la relevancia se dirime en la efectividad y la escala del cambio al que se aplica esa teoría.

- Con valores hondos, principios firmes y posición política aguda y decantada. Todo esto es indispensable, para influir, y para cualquier faceta de la vida. Sin embargo, se puede contar con todo esto y que nadie conozca la posición más que los propios miembros de la organización. $Y$ a veces ni eso.

Qué sí es una organización relevante e influyente. Una organización:

- Que aspira provocar o contribuir a cambios sistémicos. Que no se conforma con asegurar el impacto de los proyectos o programas que gestiona, sino que busca multiplicar este impacto de forma exponencial para alcanzar la escala requerida por la transformación. Sea en cualquier nivel, del municipal al global.

- Con una teoría de cambio efectiva incorporada en su quehacer, que responde a un análisis sistémico profundo y a esa expectativa de escala en la transformación.

- Que aporta un valor añadido reconocible y reconocido al menos en un componente estratégico del mix provocador de transformaciones a escala.

- Que está orientada al futuro y produce conocimiento y experiencia para ese futuro, que aprende y permite a otros aprender y que traslada y pone ese conocimiento al servicio de otros actores, públicos o privados, para la toma de decisiones o para la replicabilidad de experiencias. 
- Con el tamaño suficiente y el modelo organizativo adecuado como para tener autonomía y el poder de agencia que permite empujar alianzas, propuestas y acciones de peso.

- Con capacidad de aportar recursos a otros: aliados, movimientos, foros, redes... Respondiendo a una estrategia determinada que les permite ser influyentes junto con otros en un objetivo de cambio o meta en particular.

- Valiente e independiente. Que tiene voz para hacer valer su posición y arriesgarse con ella. Que comunica y llega, con una marca apreciada que difumina o pone en primera fila en función de la estrategia de cambio, no de la marca en sí.

- Que piensa en grande, más allá de su capacidad efectiva, con ambición e ilusión por sacudir las estructuras injustas.

- Que es referente para un determinado sector social, frente a la opinión pública, en un tema de agenda global o ante un interlocutor clave en los procesos de decisión. A quien llaman, se espera que esté y aporte, es consultada y su opinión marca un proceso.

- Que sabe construir alianzas orientadas al cambio. Que escucha. Con la humildad de quien sabe ocupar lugares secundarios si es necesario, y con la certeza de lo que puede aportar.

- Con una cultura interna que promueve la diversidad, el debate, la innovación, el ensayo. Con una estrategia tan interiorizada que le permite aprovechar las oportunidades con flexibilidad y en cuanto aparecen. Con apetito e instinto político.

Por si acaso cabe duda, no es necesario cubrir todas esas características para ser una organización relevante e influyente. De hecho, algunas lo son solo con unas pocas de estas fortalezas. Lo que sí reflejan es el marco de actuación de quien aspire no ya a la supervivencia institucional y la sostenibilidad financiera en el tiempo, sino a sumarse a las transformaciones urgentes que necesita el mundo.

\section{Un pasado de compromiso sobre el que construir}

\section{I. Primera etapa. Las misiones entre los 50 y los 70}

Es difícil fijar un año, ni siquiera una década, para el surgimiento de las ONGD en España. Las católicas, Cáritas, Manos Unidas y las de órdenes religiosas, tienen su origen en las décadas de los 50 y 60 . En su primera etapa lo social se combinó 
con lo pastoral en organizaciones completamente orientadas a dar apoyo a los misioneros españoles presentes en el entonces llamado Tercer Mundo.

A lo largo de los años 60, en las alas del Vaticano ll y con una conexión mayor con organizaciones hermanas en otros países, algunas ONG católicas evolucionaron hacia el concepto de desarrollo. En el tiempo del estructuralismo económico y del despliegue de luchas sociales, las organizaciones (aún secretariados de misiones en muchos casos) apostaron por la capacitación, los proyectos de generación de ingresos, el papel de la mujer y una mirada más profunda a las causas del "subdesarrollo" y la pobreza. Este es el caso de Intermón, llamada en esa época Misión y Desarrollo.

Sería simple e injusto, calificar a todas estas organizaciones de asistenciales y poco relevantes, más allá de la actuación con la gente que les rodeaba en los proyectos. Había mucho de esto, sí. Como también había voces valientes de religiosos y religiosas que se jugaban la piel con y por la gente con la que compartían vida. Hay cientos de ejemplos, muchos anónimos y otros conocidos como Vicente Ferrer que se enfrentó a los terratenientes en la India, los jesuitas de la UCA, o el trabajo social con un profundo impacto político de Pere Casaldáliga.

Pocas acciones son más influyentes, y arriesgadas, que una voz profética alzada desde la vida compartida con la población explotada del mundo. Su penetración, credibilidad, pasión y perseverancia, nos dicen mucho de cómo se enfrenta un sistema opresor.

\section{2. $\operatorname{Los} 80$ y 90}

La mayor parte de las ONGD no religiosas nacieron en España una vez llegada la democracia y por lo tanto con décadas de retraso respecto a otros países desarrollados. Cuando en otros lugares se llevaba tiempo en acciones de solidaridad y defensa de los derechos humanos, en España comenzaron a surgir organizaciones solidarias desde sectores profesionales, sindicatos, partidos políticos, grupos independientes y secciones de ONG internacionales que se establecieron en España. Reflejo de la gran diversidad que aún existe en este sector, y reflejo a su vez de la diversidad social de la que emergieron. Algunas de las organizaciones nacieron con un fuerte componente político en cuanto a su posición, herederas en algunos casos de las luchas antifranquistas. Otras con un concepto estrictamente solidario de su hacer hacia la pobreza. 
Es el tiempo de los cooperantes y voluntarios que a su vuelta contribuyeron a la profesionalización del sector, de las primeras convocatorias y proyectos, del inicio de la captación de recursos privados. Se fundó la Coordinadora Española de ONGD en 1986 entre un grupo diverso de organizaciones y se concibieron las primeras acciones conjuntas como sector. Es el tiempo también de la sensibilización y de los conciertos solidarios, del inicio del Comercio Justo.

Entre 1994 y 1996 sucedieron dos hechos de la mayor trascendencia para las ONGD. En 1994 las matanzas masivas de Tutsis en Ruanda cubiertas por todos los medios por su dimensión humana y brutalidad. La conciencia humanitaria, aún débil en España, se despertó a partir de esa gran crisis.

Y las huelgas de hambre y acampadas por el $0.7 \%$. Un grupo de activistas comprometidos arriesgaron su vida para exigir que España incrementara su ayuda al desarrollo y decenas de miles de jóvenes les siguieron, acampando en la Castellana de Madrid y en toda España. La influencia de estas movilizaciones en la política de Cooperación al Desarrollo permanece, por más que se haya difuminado, casi 30 años después, como lo atestigua el peso que la Cooperación Descentralizada ha tenido en España, y que surgió en su mayoría como respuesta a las acampadas en cada plaza mayor.

Cabe destacar que las ONGD no tuvieron un rol protagonista en las movilizaciones, aunque sí en la respuesta humanitaria a la terrible crisis de Ruanda. En las plazas de España fueron los muy jóvenes, inspirados por activistas mayores en huelga de hambre, quienes acamparon y no se movieron hasta que no hubo compromisos suficientemente ambiciosos en relación con la ayuda al desarrollo. Especialmente sobre su cantidad, aunque también con aspectos asociados a su calidad y participación social en esa política pública.

Dicho lo anterior, las organizaciones sí tuvieron un papel importante en tres aspectos: ampliar el alcance público de las movilizaciones; realizar informes y respaldar con datos las reivindicaciones; y apoyar las negociaciones con el gobierno y grupos políticos, aterrizando las ambiciosas propuestas de acampados y huelguistas.

Estos dos años supusieron el inicio de la relevancia pública de las organizaciones de cooperación, impulsadas por la movilización social. Abordaremos más a fondo la relación ONGs-movimientos en los siguientes capítulos, una relación que en este caso fue especialmente productiva, aunque no estuvo exenta de tensiones. Sí cabe destacar algunas lecciones de esa época en relación con la influencia sobre las políticas y la opinión pública, en el terreno de la Cooperación al Desarrollo en este caso. Entre ellas: 
- La potencia de lo épico y fuertemente simbólico, como es una huelga de hambre, para dar alcance y credibilidad a la reivindicación y para forzar a los políticos. Una potencia que conlleva el riesgo de quemar el camino por recorrer yéndose al extremo de la acción desde el inicio de la movilización, y diluyendo cualquier acción en los años siguientes.

- Esa misma radicalidad, aunque no sea replicable en forma de movilización, deja una estela de recuerdo que permitió operar a los actores de la cooperación en un clima relativamente favorable durante años. Saber aprovechar ese espacio creado, mientras dure, requiere de especial cuidado para no quemarlo ni pervertirlo y sí ensancharlo en lo posible. Cosa que se consiguió durante más de una década.

- La calle es esencial y es un terreno muy complicado para las ONGDs. Su capacidad de movilización es ancha pero no profunda, no suficiente para sacar números de personas a las calles y plazas.

- Dicho esto, se demostró que las organizaciones pueden aportar valor a una movilización reivindicativa sin necesidad de protagonizarla, siempre que sepan ocupar bien ese lugar y reconocer a quienes sí se la juegan en el centro del activismo radical.

Las movilizaciones sociales reivindicativas por "un mundo mejor y más justo", siguieron durante la década siguiente, entrando en el nuevo milenio, aunque evolucionaron en su temática y alcance. Del $0.7 \%$ destinado a cooperación, el foco se abrió a la cancelación de la deuda externa (Jubileo 2000), "Make Poverty History", la influencia sobre el Banco Mundial y el FMl, y las movilizaciones más amplias y radicales contra la globalización que tomaron como objetivo las reuniones ministeriales de la Organización Mundial del Comercio (OMC).

\subsection{La primera década de los 2000 , auge y caída de la cooperación y su influencia}

Internacionalmente son los años de la Ronda de Doha de la OMC y de los Foros de Davos y Porto Alegre, iconos del capitalismo uno, y del activismo global por la justicia, el otro. En España algunas organizaciones empezaron a tomarse en serio la influencia política como una actividad importante que requería de dotación e inserción en la teoría de cambio de las ONGD. Dicho esto, las capacidades eran aún menores, inexistentes en muchas organizaciones y centradas exclusivamente en la posición política en otras, algo con un limitado alcance efectivo por más radical que ésta sea. 
La influencia de las ONGD, con esa escasa dotación y capacidad efectiva, siguió centrada en la política de cooperación al desarrollo, que gozaba aún de una gran aceptación, ampliándose a algunos otros terrenos como el comercio de armas o la prohibición de las minas antipersonales, ligadas a la acción humanitaria. En 1998 se aprobó la Ley de Cooperación Internacional para el Desarrollo, un texto que se mantiene hasta la fecha y que logró un notable consenso en tiempos de mayoría relativa del PP y de batalla entre los Ministerios de Exteriores (diplomáticos) y Comercio (técnicos comerciales) por la responsabilidad y los fondos de la Ayuda. Situación que arroja otra lección para asuntos de leyes y presupuestos, y es que los gobiernos no son monolíticos y a veces hay oportunidades para provocar alianzas productivas en algunas agendas que no tengan un fuerte componente ideológico y/o de prioridad mediática.

En los primeros años del milenio, la relación con el gobierno de mayoría absoluta de Aznar pasó a ser de confrontación incluyendo fuertes ataques e intentos de división del sector de las ONGD que fracasaron aunque no sin provocar heridas notables entre las organizaciones.

Siempre que sea en un espacio de respeto a los $\mathrm{DDHH}$ y por más que sea duro mientras ocurre, cabe indicar que un tiempo de confrontación no es necesariamente negativo para la relevancia y la influencia a medio plazo, de las organizaciones que defienden una causa. Los mensajes principales se pueden colocar bien y alcanzan a la opinión pública ya que pueden ser contundentes y con menos matices. Hay espacio para un trabajo productivo con la oposición, tanto en alianza táctica -manteniendo la independencia partidista- como en propuestas programáticas afinadas. Todo esto requiere de resistencia para aguantar las embestidas e inteligencia política y comunicativa para aprovechar el tiempo y el espacio singular que se abre.

Esto fue lo que ocurrió en el caso de la política de cooperación con el PSOE y sobre la transparencia y control del comercio de armas con otros partidos como CiU o Iniciativa. Se sentaron las bases, sostenidas por la opinión pública, para cambios significativos cuando el PSOE llegó al poder en 2004, con el compromiso de alcanzar el $0.5 \%$ en $A O D$ y de realizar cambios notables en la calidad e instituciones de la Cooperación Española. Los avances en esa legislatura fueron muy significativos tanto en recursos como en calidad y peso político dada a la Cooperación al Desarrollo española. El compromiso firme y personal de Zapatero fue clave en este tiempo de reforma y crecimiento acelerado de fondos de Cooperación, que contó con un excelente equipo al frente, muy bien conectado con las ONGD. 
Las ONGD entraron en un período nuevo caracterizado por cuatro elementos:

- Una inyección de fondos muy significativa desde el gobierno central y, más aún, desde la Cooperación Descentralizada. El volumen de proyectos financiados, bajo la vieja y farragosa normativa de subvenciones española, sumió a las ONGD en una espiral de formulaciones y justificaciones sin fin, de la que aún no se han repuesto. Los programas, su calidad, su financiación y su justificación, se llevaron el grueso de las energías de las ONGD en detrimento de otros asuntos como la influencia política.

- Que a su vez requiere, en una etapa así, de unas propuestas y un lobby mucho más concreto y afinado, para influir en reformas que apuntan en la buena dirección, pero que no están exentas de dilemas y presiones al interior del gobierno o con otros grupos políticos.

- Riesgo de cooptación. La relación previa en tiempos de confrontación-oposición y la cercanía para trabajar propuestas concretas, incrementaron el riesgo de alinearse de fondo y de forma con el gobierno. Las ONG tuvieron que realizar un esfuerzo por mantener la independencia, con éxito desigual.

- Apertura a nuevos temas. Sin abandonar el carácter global y en relación con el Sur, las ONGD se abrieron a la influencia y las campañas sobre otros temas diferentes del propio de la Cooperación al Desarrollo. A los ya mencionados de armas y minas, o de campañas globales sobre cancelación de deuda, se sumaron los de comercio internacional, propiedad intelectual, derechos laborales y trabajo infantil en cadenas de valor globales, etc. El concepto de coherencia de políticas apareció con más fuerza.

Cabe indicar que el crecimiento de fondos y las mejoras evidentes en orientación de la política no fueron seguidas de las reformas en las instituciones de la cooperación y en las condiciones de las personas que trabajan en ellas. De nuevo una lección para la influencia. Los cambios, para ser sostenibles, necesitan de apoyo público, respaldo político, dotación presupuestaria, marco legislativo e instituciones adecuadas. Sin esto último, el resultado de las transformaciones será más fácilmente reversible.

Tras los años de crecimiento y reformas a partir de 2004, la crisis económica de 2008 tuvo un efecto demoledor sobre la Cooperación Española y las ONGD. Desde 2010 y de forma acentuada con la llegada del nuevo gobierno del PP, la AOD española se recortó en un $70 \%$, con capítulos como la Acción Humanitaria laminada al $80 \%$ y las contribuciones multilaterales voluntarias desaparecidas. 
Son tiempos de crisis económica y social aguda. La atención social y política se volcó a lo doméstico, de forma especial en todo lo relacionado con la pobreza. Las donaciones a organizaciones de acción social crecieron, las de cooperación internacional cayeron. Hacía años ya de las movilizaciones por el 0.7 , la sensibilidad y el apoyo social seguían ahí, pero se hicieron menos profundas si cabe. Los recortes brutales en la AOD se realizaron sin coste social y solo con la reacción de las organizaciones e instituciones vinculadas con la Cooperación al Desarrollo.

La crisis y los recortes tuvieron un fuerte impacto sobre las ONGD, especialmente en las más dependientes de financiación pública. Fue un tiempo de resistencia y de una influencia externa mermada por las reestructuraciones internas y adaptaciones a los nuevos escenarios financieros.

\subsection{Desde 2010. El I5M, los ODS universales y la mirada doméstica}

En este estado, de debilidad y cierta desorientación, llegaron las ONGD a los años de recuperación de la crisis económica y financiera que se inició en 2008. Cabe destacar dos elementos cruciales que definen esta década en el asunto que nos concierne: El 15M y la Agenda 2030 de los ODS.

El 15M supuso una movilización masiva frente a la precariedad, la desigualdad y el acaparamiento de riqueza y poder. En su fuerza y posición de base, conectó con movilizaciones anteriores, aunque con una diferencia sustancial. El 0.7, la deuda externa o las movilizaciones antiglobalización, así como las primeras manifestaciones ambientalistas, tenían una base claramente internacionalista y una mirada universal. Hablaban del mundo que queremos, para todas las personas, del rol de España en la arena global, de las corporaciones multinacionales y los derechos humanos en el planeta. El 15M fue doméstico y miró solo a lo estatal, lo local. Algo que resulta explicable, aunque no nos guste, teniendo en cuenta la creciente desigualdad y pobreza en España.

La Agenda 2030 por otro lado, reforzó esta mirada doméstica dado su sentido universal. Las metas de los ODS valen para Berlín, Lima, Córdoba o Nairobi, localizándolas luego en cada lugar según su situación. La diferencia en este caso, es que la Agenda es clara en tres factores determinantes, además de su universalidad.

- Se trata de desafíos globales. O sea, buena parte de ellos no se conseguirán en ningún lugar si no se consiguen en todos. Véase la lucha contra los paraísos fiscales, las vacunas o la agenda climática. 
- Se plantean de forma estructural. La solución no es solo, ni principalmente, que el "Norte" libere unos miles de millones para financiar los viejos ODMs en el Sur. Todos tenemos que cambiar estructuras, modelos de producción y de consumo, políticas y presupuestos.

- Los ODS están interconectados. Jamás se logrará el Hambre Cero sin afrontar la crisis climática con determinación y urgencia. La pobreza no se reducirá si no lo hace la desigualdad. Desigualdad y sostenibilidad son los dos límites del mismo donut.

15-M y ODS son dos factores cruciales, entre otros, que definen buena parte de la última década para las ONGD, y su capacidad para influir en las causas de la justicia social. El sector se caracterizó en este tiempo por:

- El traspaso de buena parte de las funciones asociadas con los programas de desarrollo a las organizaciones y equipos locales del sur. Se transitó de la gestión de programas (y el ciclo asociado con los mismos y sus financiadores) a aportar valor añadido en forma de calidad, innovación y conocimiento experto; y de influencia política en el patio propio además de en la arena global. Dicho esto, la captación de fondos institucionales y la relación con grandes donantes siguió en manos de las ONG del Norte.

- La opción por abrir "programas domésticos" en España por parte de la mayoría de las grandes ONGD, en parte por convicción y en parte como respuesta a la "localización" de la solidaridad y las luchas por la justicia.

- La recuperación de los recursos privados de socios individuales por parte de las organizaciones con capacidad para invertir y captar. La emergencia de nuevas formas de captación y construcción de base social asociadas a lo digital en estrategias de "engagement" más sofisticadas.

- La irrupción de la causa migratoria y de los refugiados, que ocurre en nuestras fronteras y territorios, no solo "allá lejos". Un asunto con peso propio y que además marca la posición y percepción social de las organizaciones. Una parte de la sociedad y los gobiernos animan el trabajo de desarrollo en lugares de origen para "contener" la migración (como si las personas fueran moléculas de $\mathrm{H} 20$ ), mientras se ataca a quien salva en las fronteras o atiende a migrantes y refugiados en nuestro país. La migración ha quedado como la causa más complicada para hacer pública y, desde luego, para conseguir financiación, lo que lleva a muchas ONGs a silenciarla, incluso aunque trabajen en ella.

- La política de cooperación sigue siendo irrelevante. Sus responsables tradicionales en el cuerpo diplomático no han contribuido a fortalecerla ni a fajarse 
por impulsar las reformas institucionales indispensables. El público mantiene su actitud positiva pero distante y las ONGD se abren cada vez más a otras causas y a integrar su actuación sobre la política de cooperación en asuntos mayores.

- Se refuerza el papel de los movimientos sociales y activistas individuales, como actores primarios de la presión por el cambio social. Esto al tiempo que se restringen de forma progresiva o súbita las libertades civiles y el espacio social en buena parte del mundo. La "licencia para operar" para las ONG es cada vez menos evidente en muchos países.

El resultado en términos de influencia es que buena parte de las ONGD, se quitaron la " $D$ " o convirtieron la " $D$ " en global pasando a asociarse con una agenda más amplia de sostenibilidad y justicia social que no conoce fronteras. Los temas se siguen ampliando y la interconexión se abraza con naturalidad, aunque no sin coste y sí con el riesgo de dispersión. La estela de la localización es evidente y no afecta solo a las ONGD. Así Greenpeace cada vez aborda más asuntos cercanos, Amnistía entra en temas como el de Cataluña o la Ley Mordaza, y Oxfam agarra la agenda de desigualdad en España tan fuerte como en la arena global o del sur, y con mucho más eco público y político.

La influencia de las organizaciones sociales se decanta en ese tiempo por una combinación de mayor capacidad y experiencia, y una cierta innovación en advocacy y campañas, ya bien insertas en la teoría de cambio de la mayoría de las ONG. Una capacidad aplicada a una agenda relevante para el público y la política y por lo tanto doméstica, aunque sea sin dejar de buscar el gancho con lo internacional. Se recupera la inversión en capacidad de influencia y, en algunos casos, se busca conformar "programas influyentes" que no solo tengan el apéndice de incidencia, sino que se conciban estratégicamente y desde el inicio, con la ambición de provocar cambios sistémicos a escala.

En esta situación se llega a la tercera década del milenio que se inicia pandémica.

\section{Un presente desafiante}

Las ONGD se encuentran sometidas a desafíos notables y se enfrentan a un futuro incierto. Dicho esto, hay que recordar que siguen siendo instituciones asentadas, con estructuras robustas y una financiación diversificada y, en general y por ahora, estable. Valga lo anterior para las de mayor tamaño y capacidad de inversión en captación de fondos. También para algunas de las pequeñas y medianas que 
combinan un valor añadido claro con una estructura de financiación suficientemente consolidada.

El último informe de la Coordinadora de ONGD, que agrupa a la inmensa mayoría de las organizaciones, recoge una presencia en 114 países con casi 4000 proyectos y un presupuesto total de 500 millones de euros. Una cifra que seguramente no recoge el conjunto de la financiación de las organizaciones de cooperación internacional que han diversificado donantes y salido a la arena internacional para lograr más fondos.

Dicho lo anterior, que podría indicar una situación de cierta estabilidad, las ONGD se enfrentan a un mundo trastornado por la pandemia del Covid19, que está exacerbando desigualdades existentes e incrementando la pobreza en muchas regiones. El impacto en la salud de las personas y en la economía, ha sido seguido de una respuesta fuertemente nacionalista apenas paliada por dádivas solidarias en materia de vacunas y tibios apoyos en lo financiero a través de la suspensión de pagos de deuda externa, ayudas extraordinarias del FMl y mantenimiento, a duras penas, de los flujos de AOD.

Las crisis de sostenibilidad y desigualdad se retroalimentan y, sobre todo la segunda, alienta un autoritarismo represor que se expande en las alas de las restricciones provocadas por el virus. A pesar de las señales sobre un posible cambio de paradigma en asuntos como la fiscalidad internacional, la inversión sostenible o las patentes de vacunas y tratamientos médicos, la fuerza del capitalismo extractivo y de plataforma digital sostenido por un sistema financiero sofisticado, arrasa con las haciendas públicas y concentra la riqueza en menos manos.

Este es un resumen del contexto global que, para las ONG de desarrollo españolas, se concreta en:

- Una política de cooperación que permanece bajo mínimos en volumen de recursos e interés político y social. Ni la pandemia, ni la crisis climática o fiscal logran levantar la mirada de líderes, medios de comunicación y opinión pública hacia la arena internacional y por lo tanto a la necesidad de tener una acción cooperativa fuerte, en espacios globales y en las regiones del sur más relevantes para España. Así fuera al menos por interés propio del país. El apoyo público permanece, aunque sin la profundidad y el interés efectivo como para impulsar esta política.

- Dicho lo anterior, el equipo al frente, liderado por la ministra de Asuntos Exteriores y el director de la AECID, están impulsando un proceso de reforma 
profunda de la Cooperación Española, en lo normativo e institucional. Tal vez el intento más genuino de los tiempos recientes. Estamos frente a una de las últimas oportunidades para revertir la dilución y maltrato a esta política.

- La lucha contra el cambio climático y la transición verde han ganado relevancia en la dinámica gubernamental y del sector privado. Sin embargo, la Agenda 2030 como conjunto, ha pasado de ser global y poco relevante, a principalmente doméstica y con expectativas de provocar cambios notables, a una relevancia menor y limitada a lo simbólico del pin. El peso ha pasado en buena medida al sector privado y la sociedad civil que, por más que impulsen iniciativas positivas, nunca llegarán a provocar cambios estructurales sin el empuje del gobierno.

- Las migraciones son más centrales si cabe que en las últimas dos décadas. En primer lugar, por la situación que afrontan migrantes y solicitantes de asilo en las rutas y en las fronteras europeas y españolas. Y también por la presencia de este reto en el debate público siendo uno de los principales vectores de polarización por parte de la extrema derecha racista. Como se ha visto durante la situación provocada por Marruecos en Ceuta, los migrantes son usados como moneda de cambio en las batallas diplomáticas que a su vez sesgan a la opinión pública en este asunto $y$, de forma indirecta, en cualquiera de la arena internacional. Sobre todo, de la cercana, África y Oriente Medio. La Cooperación al Desarrollo se entiende cada vez más por muchos líderes como una forma de contener las migraciones.

- La pobreza y la desigualdad se cronifican en España. Crecen en las crisis, sea la de 2008 o la pandemia, y apenas se suavizan en las recuperaciones. La precariedad del mercado laboral afecta sobre todo a los jóvenes bloqueando sus proyectos vitales y arrojando a la pobreza a quienes tienen hijos. Especialmente si son hogares de un solo progenitor o migrantes. La crisis fiscal se agudiza y sus efectos se notarán cuando mengue el apoyo del $B C E$, tiempo en el que volverá la presión para recortar.

Este momento en relación con la agenda de las ONGD en los temas que les conciernen se combina con algunas tendencias $y$, sobre todo, con desafíos específicos de las propias organizaciones. Entre ellos cabe destacar en primer lugar los asociados con la "licencia para operar" y, en cualquier caso, para hacerlo de la misma manera que en las últimas dos décadas.

El hecho es que en muchos países el espacio para la sociedad civil se estrecha. En la mayoría se aprueban leyes que restringen la libertad de las organizaciones 
sociales como paso para el acoso administrativo o jurídico. Se combinan ataques en los medios de comunicación o en espacios políticos con acusaciones de injerencia. Las ONG internacionales tienen dificultades cada vez mayores y en más países no ya para opinar abiertamente, incluso para financiar a organizaciones locales. Todo esto en un contexto de represión de libertades de prensa y expresión, persecución de organizaciones locales e incluso de asesinatos de líderes y defensoras de DDHH. No se trata solo de dictaduras de siempre o sobrevenidas, es una tendencia global presente de India a Brasil.

Sin llegar a estos extremos de cierre y represión, es mucho más frecuente que se ataque las organizaciones en cualquier país, incluido España, en cuanto toman posiciones más contundentes y visibles en relación con los derechos humanos, especialmente de migrantes, los derechos de las mujeres y la desigualdad económica y social. Una realidad que, sin ser en absoluto exclusiva de las ONGD, tensa a las organizaciones en relación con su perfil, base social y fuentes de financiación. No se trata de instituciones que estén acostumbradas a operar en el debate público cuando éste se enloda hasta extremos impensables hace dos décadas.

Finalmente, y en este caso fruto de tensiones al interior del sector, las ONG de desarrollo internacional enfrentan la exigencia de descolonizar sus estructuras y modos de hacer. La ola provocada por el "black lives matter" se ha trasladado al "decolinizing aid" en el sistema de ayuda. Los equipos, movimientos sociales y organizaciones locales de países del sur exigen una transformación de los fundamentos del sistema de cooperación. La vieja "horizontalidad" de las relaciones ya no sirve si no viene acompañada de un reequilibrio de los recursos y capacidades, así como de los procesos de toma de decisión. La "licencia para operar" en el Sur y para hablar del Sur la tienen organizaciones locales que exigen ser apoyadas, no ya en sus estrategias, sino con el grueso de los fondos generados en el norte para la solidaridad con las causas de la justicia global.

De hecho, y como una de las consecuencias de esta presión global, la mayor parte de las ONGD han afianzado sus programas domésticos. Se trata además de una respuesta a la demanda social y a la necesidad de recuperar relevancia ante el alejamiento de la sociedad de los asuntos internacionales. Una relocalización de sus agendas que a su vez contribuyen a conformar ejes temáticos o de causas que trascienden geografías. Las estrategias de entrada y posición de las ONGD en la arena nacional han sido diversas, como lo son en asuntos globales solo que, con la sensibilidad añadida de la política estatal. Las ONGD se han convertido, en buena medida, en OSC nacionales. 
A efectos de la relevancia e influencia de las ONGD, la combinación de agenda política, mirada doméstica, polarización y cierre de espacios a la sociedad civil, conlleva algunos factores y dilemas añadidos.

- Una tensión interna mayor en relación con la posición política, casi en cualquier tema. Parte del equipo y órganos de gobierno que abogan por la moderación y tender puentes, frente a otras partes de la organización que exigen respuestas firmes desde un enfoque de derechos, a vulneraciones flagrantes de los mismos, a una desigualdad extrema y al machismo.

- Tensión que se extrema a la hora de la captación de fondos. En ocasiones cuando la dependencia de fondos públicos es excesiva, ante el riesgo de ser excluidos por las administraciones públicas. Y, sobre todo, en relación con los recursos privados de socios y donantes. La alta sensibilidad y polarización del debate público en medios y redes sociales y la opción de las ONGD de contar con bases amplias de socios y donantes, marca las decisiones de agenda pública y tono político. A modo de ejemplo, la causa migratoria apenas es tomada como vehículo para captar fondos e incluso es silenciada por algunas organizaciones por los riesgos de ataque que conlleva.

- Las organizaciones sufren el mismo desgaste que otras instituciones frente al mundo digital que lamina intermediarios y cercena fidelidades. En el terreno de la movilización y la influencia pública, el activismo de movimientos sociales e individuos que se asocian con causas renueva sus energías. Dicho esto, las ONG aún son capaces de poner en juego sus fortalezas (cercanía con las causas/ legitimidad, conocimiento profundo, capacidad institucional y política), para mover cambios políticos muy significativos. O para influir en normas sociales a una velocidad notable e impensable para otros actores.

- Las grandes alianzas sobre grandes temas -ODS, Cambio Climático...- se mantienen y son capaces de aglutinar a muchas organizaciones y otros actores, aunque no logran marcar la agenda pública con la intensidad necesaria para provocar cambios.

- Todo lo anterior apunta a un riesgo de despolitización de la influencia, más técnica, más amplia y con más capacidades, mejor inserta en los programas globales de las organizaciones, pero con la posibilidad de perder pegada, y en alguna medida olfato y flexibilidad, para operar en la dura arena política de hoy. El camino de buscar el impacto a escala a través del conocimiento, la innovación y las alianzas multi-actor, se hace más atractivo y menos sensible para algunas ONG. 


\section{Un futuro en cambio constante que requiere determinación}

El momento que vive la sociedad, global y en España, somete a las ONGD a las tensiones indicadas en el capítulo anterior. El riesgo a $4 \circ 5$ años de muchas organizaciones pequeñas y medianas es el de una fragilidad institucional y financiera que las lleve a la desaparición o a una crisis de supervivencia permanente en la que solo cabe pensar en el siguiente proyecto cofinanciado. Teniendo en cuenta los previsibles vaivenes, recortes y cambios en la financiación institucional de las ONGD, la amenaza de quiebra puede hacerse realidad para algunas. Depender de convocatorias generalistas de proyectos es tan antiguo como arriesgado.

Estas organizaciones de tamaño mediano o pequeño, la mayoría de las que pueblan el tejido de las ONGD españolas, deberán afianzar su especialización y valor añadido en una o máximo dos aspectos asociados con funciones (movilización, estudios, evaluación...) y sobre todo con temas concretos, donde se hagan referentes por su conocimiento experto y capacidad de innovación. La especialización geográfica, o sea tener mucha presencia y relaciones en un país/región del Sur, de la que muchas han vivido durante décadas, ha dejado de tener sentido. Sería recomendable que contengan sus estructuras, incluso en tiempos de bonanza, y que fortalezcan sus alianzas con otros actores, públicos y privados, que, además de aportar impacto a los programas, apoyen a las organizaciones frente a nuevas crisis. Complementar su actuación internacional con algún tipo de intervención en España puede tener sentido para estas organizaciones, si se hace de forma estratégica y no ocasional y si se vincula con programas de construcción de Ciudadanía extensos, bien conectados en los territorios.

El riesgo de las de mayor tamaño no es la desaparición sino la irrelevancia, camuflada bajo la comodidad de seguir siendo consultadas de vez en cuando por la política y los medios de comunicación. Sin estar exentas de crisis por caídas de la financiación, sobre todo de la privada y libre, las "Big NGOs" seguirán siendo instituciones de peso y dimensión en el futuro previsible. Algunas incluso crecerán en socios y recursos a través de la inversión un fundraising agresivo y la potencia de marca. La evolución de su estrategia programática y de alianzas con otros actores que llegan a la cooperación, les ofrece oportunidades de mantener niveles de financiación y relación con los principales donantes institucionales y corporativos a través de programas multi país con un fuerte componente de innovación y experiencia temática decantada. Es previsible que estas organizaciones, las de mayor capacidad de respuesta humanitaria, mantengan su espacio y financiación 
en este terreno, al menos mientras no se avance en la localización de la acción humanitaria a través de organizaciones y actores locales. Un proceso que avanza con lentitud extrema.

A continuación, se recogen una serie de propuestas para este grupo de organizaciones de mayor tamaño, de cara a fortalecer su influencia y relevancia pública en los próximos años:

1) Reforzar su actuación doméstica en España, y hacerlo junto con otras organizaciones de la sociedad civil, normalmente más débiles financieramente pero más enraizadas en las causas, territorios y fronteras. La tentación a vencer es la de generar programas "utilitaristas" vinculados exclusivamente con la marca y la financiación exitosa a través de la imagen de acción social doméstica. El desafío es la integración estratégica a través de cada causa, de lo que se haga en España con lo que se impulse en la arena internacional, y con el trabajo de influencia asociado.

2) De hecho, intervenir en lo doméstico, si se hace con la estrategia y el hilo narrativo adecuado, debe servir para reforzar el carácter global de los programas y para explicar lo que ocurre en otros países, levantando así la mirada a lo internacional. Cada vez quedan menos causas que se enfrenten "solo alli" o "solo en España". El cambio climático, el machismo, el racismo, la injusticia fiscal, la erosión de salarios y condiciones laborales...son desafíos que debemos enfrentar donde se produzcan, que es en todo el mundo. Este es el sostén actual de la política de cooperación internacional que debemos seguir defendiendo, el del abordaje colectivo de bienes públicos globales en los que la humanidad, también España, se la juega.

3) La dimensión de estas organizaciones les permitiría seguir los dos caminos para ser influyentes y relevantes: el del expertise temático o funcional, la innovación y las alianzas multiactor para desarrollar programas de alto impacto; $y$ el de la influencia social y política para provocar cambios estructurales en los sistemas que sostienen la injusticia. Dicho esto, no es fácil ser muy bueno en ambos terrenos, que exigen un set de prioridades y capacidades diferentes. Como hemos indicado, el riesgo actual es el de la deriva hacia el conocimiento y la innovación programática, menos arriesgada que la influencia social y política. Cabe indicar, además, que hay nuevos actores universitarios, científicos, consultoras, empresas, que han emergido con fuerza en el terreno del conocimiento influyente y las alianzas para contribuir a las metas de los ODS. Ese terreno se va a llenar. 
4) La propuesta por lo tanto es que las ONGD no solo no diluyan, sino que refuercen sus capacidades y apuestas por la influencia social y política con todos los riesgos, oportunidades y tensiones que esto trae consigo. Es más, considero que esta opción es si cabe más importante hoy que nunca. Lo que en su origen fue un complemento importante a la acción programática, en la adopción del enfoque de derechos, hoy es esencial para ser capaces de provocar cambios reales y para mantener un espacio propio como actor social reconocido.

5) El umbral de riesgo en relación con la financiación debería rebajarse, aunque sea algo a tener en cuenta, sobre todo para no correr riesgos innecesarios por acciones inútiles que pueden provocar reacciones adversas. Hay organizaciones, como Save the Children España, que han demostrado estos años que se puede crecer en recursos privados al tiempo que se mantiene una capacidad de influencia pública más que significativa y en asuntos tan sensibles como el abuso sexual en la infancia. Es un hecho que la causa de la infancia es buena para la captación, que invierten y que lo hacen con una agresividad tal vez excesiva. Sin embargo, también es cierto que esta organización se la ha jugado varias veces con acciones y posiciones visibles y de riesgo. La conclusión es que, si el fundraising privado de las organizaciones domina por completo el perfil externo, la combinación de aversión al riesgo (polarizaciones, ataques, perfil político...) y de énfasis comunicativo en según qué temas y cómo, diluirán las opciones de estas organizaciones de ser relevantes e influyentes en la arena pública. Algo que es hoy más necesario que nunca. Así que toca decidir.

6) En esa decisión radica la apuesta por el tipo de perfil externo, la base social que se quiere construir y la prioridad por unos públicos $u$ otros dentro del magma y diversidad en la sociedad. Es indispensable renovar la base social generacionalmente y esto, los canales, actuaciones y propuestas, puede exigir tensarla por el lado de mayor edad y perfil conservador.

7) En el terreno específico de la influencia social y política (incidencia, campañas, lobby...) los desafíos son también notables. Para afrontarlos es esencial reforzar las capacidades organizativas específicas para estas funciones. No toda persona tiene liderazgo y olfato político, base de conocimiento capacidad de movilización, relación, flexibilidad y sentido de la oportunidad pública. Independientemente del tipo de estructura organizativa que se adopte, departamentos, matrices y redes internas, es indispensable contar en el equipo con personas de estos perfiles que lideren a la organización en este terreno. 
8) Los roles que se pueden y deben jugar se han diversificado y no están predeterminados, ya que dependen del momento políitico, los objetivos y las alianzas. Las organizaciones deben estar dispuestas a manejar su marca y exposición pública al servicio de los objetivos de cambio y no a la inversa, como ocurre más de una vez. Las organizaciones aliadas, tanto en España, la arena global y en los países del Sur, nos exigen evolucionar en nuestro modo de hacer. Mantener nuestras apuestas políticas, pero escuchar más, apoyar los momentos y actuaciones de otros, y no esperar que solo se apoyen los propios, transferir recursos libres que permitan el trabajo de influencia a otros y no usarlos solo al interior de las organizaciones. No se trata de desaparecer para convertirse en un donante, aunque ocasionalmente esa pueda ser nuestra principal función. Se trata de saber jugar el papel que nos toca en cada momento, subsumir la marca o sacarla con fuerza, defender con voz propia o crear espacio para la voz de otros, aportar aspectos concretos a movilizaciones en las que otros son los actores centrales. Una forma de hacer que exige tanta humildad como estrategia e inteligencia política.

9) Dicho lo anterior, sigue habiendo muchos momentos en los que se exige a las organizaciones valentía para posicionarse sin duda al lado de quienes ven sus derechos vulnerados, quienes sufren la desigualdad y el acaparamiento de recursos y riqueza. También en la causa de los migrantes y refugiados que se ahogan frente a nuestras costas y cuyas rutas recogen todas las causas que se deben defender. A pesar de las tensiones fruto de la polarización y de la manipulación informativa, las organizaciones tendrán sentido, y serán consideradas actores relevantes, si son consistentes y contundentes en sus posiciones externas, sobre todo en determinados momentos. Ello las llevará con toda seguridad a ser acusadas de partidistas e incluidas en el lodazal en el que se ha convertido la vida política. Bien, es inevitable, también hay que saber operar en el lodazal si nos queremos embarrar en los asuntos que importan.

10) Los cambios sociales y tecnológicos exigirán a las organizaciones una fuerte capacidad para innovar en sus estrategias y formas de hacer influencia social y política. Un advocacy más abierto y transparente que rinda cuentas de la misma forma que exige esa rendición de cuentas, el monitoreo de compromisos, planes y anuncios hechos por gobiernos y empresas. Formas innovadoras de movilización social que conecten llamados a la acción robustos en su trascendencia política, épica y visibilidad, con propuestas y canales diferentes (juegos, celebridades comprometidas...) para llegar a la gente, sobre todo joven, en lo digital pero también fuera del mundo virtual. Y esa capacidad para apoyar las acciones de otros, sean activistas afamadas o los miles de jóvenes que se mueven por la justicia social a su manera. 
La agenda es la de los grandes desafíos de la sostenibilidad y la desigualdad, que definen la misión central de estas organizaciones: la lucha contra la pobreza y la defensa de los derechos humanos. Las organizaciones tendrán que seguir siendo relevantes en temas tan dispares como la financiación del desarrollo, la inversión sostenible, el cambio climático en todas sus facetas, el mercado laboral, la fiscalidad, la equidad racial y de género, y los conflictos. Una política de cooperación robusta, influyente y creíble, como parte de una agenda estatal de desarrollo sostenible es esencial para cumplir con las responsabilidades que le tocan a España.

No será fácil avanzar en los ODS y la justicia social en España y desde España sin una contribución significativa de las grande ONGD. Las cuales sucumbirán a la irrelevancia de ser una institución caduca más, si no se suman con inteligencia política y coraje a las luchas de nuestro tiempo. 